\title{
ĐÀO TẠO NGUỒN NHÂN LỰC DU LỊCH CHẤT LƯợNG CAO TRONG XU THẾ HỘI NHẬP VÀ CUỘC CÁCH MẠNG CÔNG NGHIỆP 4.0
}

\author{
Lê Thị Lệ
}

Tóm tắt: Trong xu thế hội nhập quốc tế và ảnh hưởng của cuộc cách mang công nghiệp 4.0, nguồn nhân lục du lịch chất lượng cao giữ vai trò quyết định cho sụ phát triển du lịch và góp phần không nhỏ vào việc thực hiện công cuộc đổi mới đất nước. Bài viết phân tích thực trạng đào tạo nguồn nhân lực du lịch ở nước ta, nhũng thành tưu và nhũng hạn chế, đồng thời phân tích sự ảnh hưởng của cuộc cách mạng công nghiệp 4.0, đặt ra yêu cầu và co hội cho việc đào tạo nguồn nhân lực du lịch chất lượng cao, trên cơ sở đó đề xuất một số giải pháp nhằm tạo sụ đột phá trong đào tạo nguồn lực du lịch chất lượng cao thời kỳ hội nhập, để góp phần đura ngành du lịch trở thành ngành kinh tế mũi nhọn.

Từ khóa: Nguồn nhân lục, du lịch, đào tạo nguồn nhân lục, du lịch hội nhập, công nghiệp 4.0.

Ban Biên tập nhận bài: 11/12/2019 Ngày phản biện xong:12/12/2019 Ngày đăng bài: 20/12/2019

\section{1. Đặt vấn đề}

Du lịch là một trong những ngành kinh tế có vai trò quan trọng đặc biệt đóng góp vào sự thành công của quá trình hội nhập và có vị thế quan trọng, là “cầu nối” tạo được sự gắn kết giữa các dân tộc, quốc gia... Hội nhập quốc tế về du lịch của Việt Nam thời gian qua được triển khai theo hướng thúc đẩy ký kết và thực hiện các hiệp định thỏa thuận hợp tác cấp chính phủ, cấp ngành song phương và đa phương, tranh thủ hợp tác, hỗ trợ của các nước thông qua các chương trình, dự án cụ thể và các cam kết mở cửa tự do hóa thương mại dịch vụ du lịch trong các khuôn khổ WTO, ASEAN, APEC... Bên cạnh đó, trước bối cảnh cách mạng công nghiệp 4.0, một trong những giải pháp đột phá để nâng cao tính cạnh tranh, ngành Du lịch Việt Nam sẽ cần phải ứng dụng công nghệ thông tin mạnh hơn nữa, phát triển du lịch thông minh, phát triển chính quyền điện tử, đổi mới môi trường phục vụ, hỗ trợ doanh nghiệp khởi nghiệp sáng tạo. Điều này phụ thuộc rất nhiều vào việc đào tạo và sử dụng nguồn nhân lực du lịch có chất lượng cao để có thể nắm bắt cơ hội, đối diện với thách thức tạo ra các sản phẩm đáp ứng nhu cầu ngày càng đa dạng của du khách.

\section{Lý luận về vấn đề nghiên cứu}

Đào tạo nguồn nhân lực du lịch chất lượng cao là mục tiêu hướng tới của nhiều quốc gia phát triển du lịch trọng điểm, trong đó có Việt Nam. Quan điểm về phát triển nhân lực du lịch cũng đã được thể hiện rất rõ trong các Nghị quyết của Đảng và Nhà nước. Để tăng cường phát triển du lịch, ngay từ những năm 80 của thế kỷ trước, nguồn nhân lực cũng đã được quan tâm tập trung phát triển để đáp ứng với tình hình phát triển du lịch. Thực hiện quan điểm của Nghị quyết Đại hội Đảng toàn quốc lần thứ VI, Nghị quyết số 63-HĐBT ngày 11 tháng 4 năm 1987 của Hội đồng Bộ trưởng (nay là Chính phủ), đã nêu thực trạng tình hình nguồn nhân lực du lịch với những hạn chế, chỉ đạo ngành $\mathrm{Du}$ lịch cần tập trung tháo gỡ các khó khăn, vướng mắc để tập trung các điều kiện phát triển du lịch trong đó đối với nguồn nhân lực. Trong phương hướng, nhiệm vụ chỉ đạo ngành Du lịch, Nghị quyết số 45/NQ-CP cũng đã xác định ngành $\mathrm{Du}$ lịch cần: “... Đổi mới công tác đào tạo, bồi dưỡng cán bộ và nghiên cứu khoa học phát triển du lịch".

Bên cạnh xu thế của cuộc Cách mạng công nghiệp 4.0, việc tăng cường năng lực tiếp cận

\section{${ }^{1}$ Truoòng Đại học Văn hóa, Thế thao và Du lịch Thanh Hóa}

Email: lethiledhvhttdl@gmail.com 
cuộc Cách mạng công nghiệp 4.0 và giảm thiểu những tác động tiêu cực của làn sóng này ở Việt Nam, trong đó nêu rõ du lịch là một trong những ngành kinh tế được ưu tiên xây dựng chiến lược chuyển đổi số, ứng dụng công nghệ thông tin nhằm thúc đẩy du lịch thông minh ở Việt Nam. Thủ tướng Chính phủ đã ban hành Chỉ thị số 16/CT-TTg ngày 4/5/2017 và Quyết định số 1671/QĐ-TTg ngày 30/11/2018 ban hành "Đề án tổng thể ứng dụng công nghệ thông tin trong lĩnh vực du lịch giai đoạn 2018-2020, định hướng đến năm 2025”. Đây là định hướng chính sách quan trọng cho ngành du lịch hướng tới các mục tiêu do Nghị quyết số 08-NQ/TW ngày 16 tháng 01 năm 2017 của Bộ Chính trị về phát triển du lịch trở thành nền kinh tế mũi nhọn trong 8 nhiệm vụ, cũng đã dành một nội dung quan trọng đối với việc phát triển nguồn nhân lực du lịch đã đặt ra [1]. Công trình nghiên cứu về đào tạo nguồn nhân lực du lịch trong bối cảnh hội nhập của tác giả Phạm Trung Lương [6] đã khái quát hóa về công tác đào tạo nguồn nhân lực du lịch hiện nay và phân tích những ảnh hưởng của quá trình hội nhập khu vực ASEAN đến hoạt động du lịch. Dưới tác động của cuộc cách mạng công nghiệp 4.0 nhiều lĩnh vực du lịch mới ra đời (như du lịch trực tuyến, du lịch thông minh, du lịch 4.0) đem lại hiệu quả vượt trội so với trước đây [5]. Kỉ yếu Hội thảo khoa học "Phát triển du lịch trong cách mạng công nghiệp 4.0“ đã đề cập đề các vấn đề của du lịch, trong đó TS. Lê Sĩ Trí đã nêu ra sự cần thiết việc quảng bá du lịch với những vấn đề đặt ra và kiến nghị để du lịch Việt Nam đáp ứng được trong tình hình mới [9].

Năm 2019, trong kỉ yếu hội thảo "Phát triển nguồn nhân lực du lịch chất lượng cao trong bối cảnh hội nhập quốc tế" tại TP Hồ Chí Minh, PGS.TS Lê Anh Tuấn đã phân tích các vấn đề về chủ trương, đường lối chính sách của Đảng và Nhà nước về phát triển nguồn nhân lực du lịch, việc nâng cao chất lượng nguồn nhân lực đã đáp ứng yêu cầu của thực tiễn phát triển ngành $\mathrm{du}$ lịch nhưng còn nhiều vấn đề tồn tại [10]. Phát triển nhân lực du lịch chất lượng cao trong bối cảnh hội nhập cũng được PGS.TS Phạm Xuân Hậu đề cập trong việc đưa ra các giải pháp đột phá phù hợp [3].

Phạm vi nội dung nghiên cứu tập trung làm rõ thực trạng đào tạo và sử dụng nguồn nhân lực du lịch trong xu thế hội nhập, những vấn đề đặt ra trước ảnh hưởng của cuộc cách mạng 4.0, những giải pháp để nâng cao chất lượng nguồn du lịch đáp ứng nhu cầu của khách du lịch, đặc biệt khách quốc tế.

\section{Phương pháp nghiên cứu}

Để nghiên cứu vấn đề đào tạo nguồn nhân lực du lịch trong xu thế hội nhập và cuộc cách mạng công nghiệp 4.0, các phương pháp sau được thực hiện.

\subsection{Phương pháp thu thập tổng hợp tài liệu}

Nghiên cứu thu thập tài liệu từ các nguồn tư liệu sách, báo, tạp chí và các Quyết định của Chính phủ về du lịch và đào tạo nguồn nhân lực chất lượng cao nói chung và nguồn nhân lực du lịch của Việt Nam nói riêng, cụ thể là: các quyết định của Chính phủ về việc phê duyệt Quy hoạch tổng thể phát triển du lịch Việt Nam đến năm 2020, tầm nhìn đến năm 2030, các Nghị quyết của Đảng về du lịch, các báo cáo hàng năm của Viện nghiên cứu phát triển du lịch...

\subsection{Phuơng pháp phân tích, xử lý số liệu}

Trên cơ sở số liệu nguồn nhân lực từ các tài liệu tổng hợp, nghiên cứu tiến hành thống kê và xử lý dữ liệu về số lượng và chất lượng nguồn lao động du lịch, lượng khách du lịch,... các biểu đồ trực quan thông qua phần mềm Excel; thống kê và tính toán tốc độ tăng trưởng lao động du lịch.

\subsection{Phương pháp so sánh, đánh giá}

Phân tích, xử lý các số liệu kinh tế, so sánh tốc độ tăng trưởng nguồn lao động du lịch qua các năm, năm sau với năm trước của Việt Nam với một số nước trong khu vực về khách quốc tế đến.

\subsection{Phương pháp chuyên gia}

Thực hiện bằng lấy ý kiến của các đơn vị sử dụng lao động du lịch, các nhà quản lý lĩnh vực du lịch thuộc Bộ Văn hóa Thể thao và Du lịch; Tổng cục du lịch; Viện nghiên cứu phát triển du 


\section{BÀI BÁO KHOA HỌC}

lịch... Nội dung chủ yếu liên quan đến: Chiến lược và Chính sách phát triển nguồn nhân lực du lịch, những vấn đề đặt ra và các giải pháp đào tạo, sử dụng nguồn lao động du lịch chất lượng cao.

\section{Kết quả nghiên cứu}

4.1. Phân tích thục trạng đào tạo và sử dụng nguồn nhân lục du lịch

Nguồn nhân lực du lịch bao gồm đội ngũ quản lý trong các cơ quan quản lý nhà nước về du lịch; Lao động quản lý các doanh nghiệp; Lao động nghiệp vụ (Lễ tân; Phục vụ buồng; bàn, bar; Nhân viên nấu ăn; Hướng dẫn viên; Nhân viên lữ hành, đại lý du lịch; Nhân viên khác) và lao động sự nghiệp (các nghiên cứu viên hoạt động trong lĩnh vực nghiên cứu liên quan, các giáo viên, giảng viên các cơ sở đào tạo du lịch) [2].

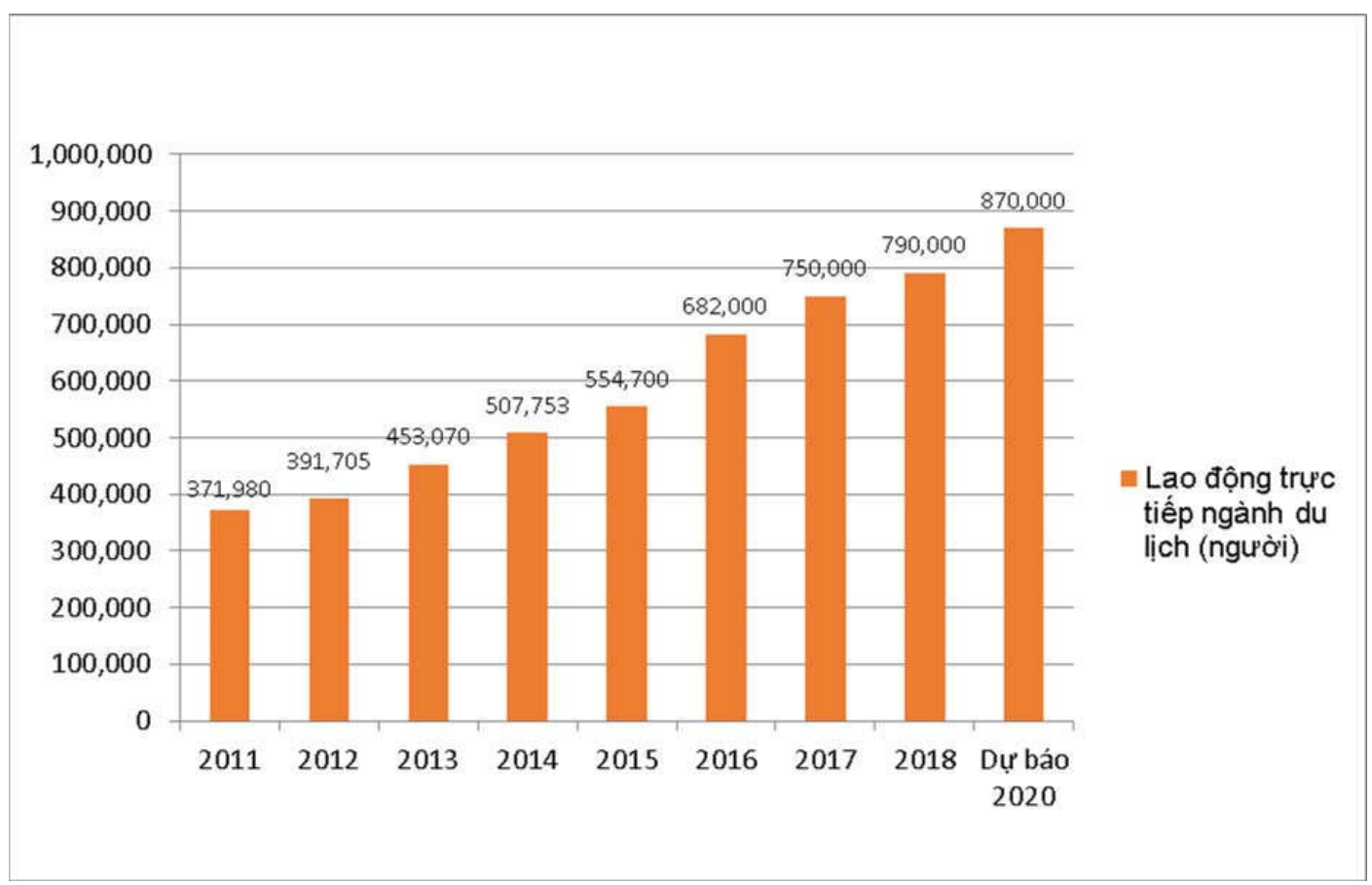

Hình 1. Lao động trục tiếp trong ngành du lịch giai đoạn 2011-2020 [11]

Bảng 1. Nhu cầu nhân lực ngành du lịch $[8,11]$

\begin{tabular}{|c|c|c|c|c|c|c|}
\hline STT & Chỉ tiêu & $\begin{array}{c}\text { Năm } 2010 \\
\text { (người) }\end{array}$ & $\begin{array}{c}\text { Năm } 2015 \\
\text { (người) }\end{array}$ & $\begin{array}{c}\text { Tỷ lệ } \\
(\%)\end{array}$ & $\begin{array}{l}\text { Năm } 2020 \\
\text { (người) }\end{array}$ & $\begin{array}{l}\text { Tỷ lệ } \\
(\%)\end{array}$ \\
\hline & Tổng số & 418.250 & 620.100 & 9,6 & 870.300 & 8,1 \\
\hline \multicolumn{7}{|c|}{ Nhu cầu nhân lục ngành du lịch theo trình độ đào tạo } \\
\hline & Trên đại học & 1.450 & 2.400 & 13,1 & 3.500 & 9,2 \\
\hline & Đại học, cao đẳng & 53.800 & 82.400 & 10,6 & 113.500 & 7,5 \\
\hline & Trung cấp và tương đương & 78.200 & 115.300 & 9,5 & 174.000 & 10,2 \\
\hline & Sơ cấp & 98.700 & 151.800 & 10,7 & 231.000 & 10,4 \\
\hline & Dưới sơ cấp (học nghề tại chỗ) & 187.450 & 268.200 & 8,6 & 348.300 & 5,9 \\
\hline \multicolumn{7}{|c|}{ Nhu cầu nhân lục ngành du lịch theo vị trí việc làm } \\
\hline & Lao động quản lý & 32.500 & 56.100 & 14,5 & 83.300 & 9,7 \\
\hline & Lao động nghiệp vụ & 387.100 & 564.000 & 9,2 & 787.000 & 7,9 \\
\hline & 1) Lễ tân & 37.200 & 51.000 & 7,4 & 69.500 & 7,2 \\
\hline & 2) Phục vụ buồng & 48.800 & 71.500 & 9,3 & 98.000 & 7,4 \\
\hline & 3) Phục vụ bàn, bar & 68.400 & 102.400 & 9,9 & 153.000 & 9,8 \\
\hline & 4) Chế biến món ăn & 35.700 & 49.300 & 7,6 & 73.400 & 9,7 \\
\hline & 5) Hướng dẫn & 20.600 & 30.800 & 9,9 & 45.000 & 9,2 \\
\hline & 6) VPDL, ĐL lữ hành & 31.100 & 52.600 & 13,8 & 81.400 & 10,9 \\
\hline & 7) Nhân viên khác & 145.300 & 206.400 & 8,4 & 266.700 & 6,0 \\
\hline
\end{tabular}


Hiện nay, cả nước có trên 1,3 triệu lao động du lịch; trong đó có gần 800 nghìn lao động trực tiếp, mức tăng trưởng bình quân nhân lực du lịch 2011- 2018 là 12,3\% (Hình 1), chiếm 2,5\% tổng số lao động cả nước. Theo ước tính, đến năm 2020 để theo kịp nhu cầu, ngành du lịch sẽ cần khoảng 40.000 lao động một năm [2]. Dự báo thời gian tới tốc độ tăng trưởng của ngành đạt từ 25\%-35\%/năm và theo kế hoạch đến năm 2020 ngành du lịch cả nước sẽ cần đến trên 2 triệu lao động chất lượng cao, chưa kể hàng ngàn lao động cung cấp cho du lịch tàu biển.

* Về kết quả đạt được trong đào tạo nhân lực du lịch

Tính đến năm 2019, cả nước có hơn 190 cơ sở đào tạo du lịch và tham gia giáo dục đại học (ĐH), giáo dục nghề nghiệp du lịch ở trình độ đại học, cao đẳng, trung cấp, sơ cấp và đào tạo ngắn hạn, cả nước có “62 trường đại học, 80 trường cao đẳng, trong đó có 8 trường cao đẳng nghề, 117 trường trung cấp, trong đó có 12 trường trung cấp nghề, 2 công ty đào tạo và 23 trung tâm có tham gia đào tạo nghiệp vụ du lịch" [7].

Hiện nay, ở Việt Nam chưa có 1 trường nào chỉ chuyên đào tạo về lĩnh vực du lịch và có tên trường Du lịch ở trình độ $\mathrm{H}$ ngoài Trường $\mathrm{ĐH}$ Văn hoá, Thể thao và Du lịch Thanh Hoá. Tuy nhiên các ngành đào tạo về du lịch như: Du lịch, Quản trị khách sạn, Quản trị nhà hàng, Quản trị du lịch lữ hành, Việt Nam học ... lại có ở rất nhiều trường Đại học. Tại các trường Đại học, với xu thế tiếp cận với các chương trình đào tạo tiên tiến của thế giới và nghiên cứu thực tiễn của nhu cầu nhân lực du lịch, các ngành đào tạo về $\mathrm{du}$ lịch, sinh viên ra trường có thể đảm nhận được các vị trí như: Hướng dẫn viên du lịch; Điều hành du lịch: nghiên cứu thị trường, xây dựng các sản phẩm (chương trình du lịch, sự kiện...), tổ chức các hoạt động marketing và bán sản phẩm liên quan đến lĩnh vực du lịch; Quản lí doanh nghiệp lữ hành: từ hoạch định đến điều hành việc thực hiện chiến lược, kế hoạch kinh doanh du lịch; Lễ tân, Nhân viên các bộ phận tại các khách sạn; Quản lý, trưởng bộ phận tại các khách sạn, khu nghĩ dưỡng; Giảng dạy, nghiên cứu về lĩnh vực du lịch, khách sạn... Song số sinh viên tập trung đông và ra trường có việc làm đúng ngành sau khi tốt nghiệp phân bổ chủ yếu ở các trường Đại học có thương hiệu ở Hà Nội và phụ cận, TP Hồ Chí Minh như: ĐH Hà Nội, ĐH Khoa học Xã hội và Nhân văn- ĐH Quốc Gia Hà Nội, ĐH Kinh tế quốc dân, ĐH Hạ Long, ĐH Tài Chính- Maketinh, ĐH Văn hóa, ĐH Tôn Đức Thắng, ĐH Kinh tế TP Hồ Chí Minh... Khu vực miền Trung chủ yếu đào tạo du lịch tập trung tại Trường ĐH Văn hóa, Thể thao và $\mathrm{Du}$ lịch, ĐH Đà Nẵng, ĐH Huế.

Bên cạnh hệ thống đại học thì các Trường Cao đẳng và Trung cấp nghề, các Trung tâm đào tạo nghề du lịch chiếm thế mạnh, có tỉ lệ lớn với số lượng người học tham gia đông nhất, tập trung ở những địa phương có tiềm năng và thế mạnh phát triển du lịch ở Quảng Ninh, Hà Nội, Đà Nẵng, TP Hồ Chí Minh như: Cao đẳng nghề $\mathrm{du}$ lịch Sài Gòn, Cao đẳng Du lịch Hà Nội, Trường Trung cấp nghề Du lịch và Khách sạn Sài Gòn, Công ty Sài Gòn Tourist.., bởi những lợi thế về đội ngũ giảng dạy, kĩ năng thực hành đáp ứng chuẩn đầu ra, thời gian học nhanh...đang chiếm lợi thế.

Trung bình hàng năm các cơ sở tuyển khoảng hơn 22.000 học viên, sinh viên, trong đó: khoảng 5.000 đại học và cao đẳng; 18.000 trung cấp và khoảng 5.000 sơ cấp nghề. Số sinh viên, học viên tốt nghiệp hàng năm khoảng hơn 20.000 người, một lực lượng lao động trình độ và chất lượng cao cho ngành. Chất lượng sinh viên và học viên sau khi ra trường đã có chuyển biến tích cực, được các doanh nghiệp đánh giá cao; tỷ lệ có ra trường có việc làm với bức tranh sáng dần, trong đó khoảng $70 \%$ trình độ đại học và cao đẳng; $80 \%$ trung cấp.

Liên kết đào tạo giữa các trường trong nước với các quốc gia trong khu vực và quốc tế thông qua các dự án như: Dự án EU tài trợ tổ chức bồi dưỡng được khoảng 700 cán bộ đào tạo viên, 140 cán bộ quản lý nhà nước về du lịch, 600 cán bộ quản lý ngành, 160 giảng viên tiếng Anh; đào tạo được 3.337 học viên (là giảng viên, giáo viên ngành du lịch); đa phần giảng viên, giáo viên được gửi đào tạo tại các nước Luxembourg, Sin- 
gapore, Malaysia, Úc, New Zealand, Áo, Thụy sỹ..là những nước du lịch mạnh.

Chủ trương xã hội hóa việc đào tạo nguồn lực du lịch đã ra đời nhiều loại hình đào tạo năng động, hiệu quả như: bồi dưỡng nghề du lịch ngắn hạn, tổ chức bồi dưỡng nâng cao trình độ chuyên môn, nghiệp vụ, ngoại ngũ̃, kỹ năng mềm cho giảng viên, cán bộ quản lý (khoảng 1.850 người).

Đội ngũ giảng viên, giáo viên, đào tạo viên du lịch ngày một lớn mạnh về số lượng và chất lượng từng bước được nâng cao. Hiện nay, cả nước có "khoảng 5.000 người tham gia đào tạo về du lịch, trong đó có 2.000 giảng viên, giáo viên, 2.580 đào tạo viên và 540 cán bộ quản lý, phục vụ đào tạo các cấp, những người có trình độ thạc sĩ du lịch trở lên chiếm 13\% [7].

Các cơ sở đào tạo đã chú trọng đầu tư về co sở vật chất, trang thiết bị phục vụ nghiên cứu, giảng dạy và học tập để nâng cao chất lượng đào tạo, có khách sạn, nhà hàng để học viên thực tập, áp dụng chương trình tiêu chuẩn kỹ năng nghề VTOS để đưa nhân lực du lịch Việt Nam hội nhập nhanh chóng với khu vực và thế giới.

\section{* Nhũng khó khăn, hạn chế}

Sự mở rộng mạng lưới các trường Đại học đào tạo với các ngành lĩnh vực du lịch đã đáp ứng nhu cầu xã hội về nguồn nhân lực du lịch có trình độ và chất lượng cao, tuy nhiên cũng đặt ra những bất cập khi nhiều trường đại học còn thiếu đội ngũ giảng viên giảng dạy chuyên ngành, chương trình đào tạo chưa cân đối với rèn nghề nên chưa đáp ứng được chuẩn đầu ra.

Nguồn nhân lực du lịch Việt Nam thiếu về mặt số lượng, mà còn yếu về chất lượng. Hiện nay chỉ có $42 \%$ lao động đang hoạt động trong ngành được đào tạo chuyên môn nghiệp vụ về du lịch, $38 \%$ được đào tạo từ các ngành khác chuyển sang và khoảng $20 \%$ chưa qua đào tạo chính quy mà chỉ được huấn luyện tại chỗ. Trong đó, lao động trực tiếp của ngành du lịch chủ yếu trình độ sơ cấp và cao đẳng, chiếm $51 \%$ [7]. Khả năng đáp ứng về chuyên môn nghề nghiệp của lao động còn thấp; đặc biệt khả năng ứng dụng công nghệ thông tin và sử dụng ngoại ngũ̃ vào nghiệp vụ chuyên môn còn rất hạn chế. Số người sử dụng được ngoại ngữ đạt khoảng $60 \%$ tổng nhân lực, trong đó nhiều nhất là tiếng Anh khoảng $42 \%$, thiếu trầm trọng nguồn nhân lực du lịch biết các ngôn ngữ khác như tiếng Hoa chỉ có $5 \%$, tiếng Pháp là $4 \%$, và các tiếng khác là $9 \%$. Riêng tiếng Anh thì chỉ có $15 \%$ đạt trình độ đại học, giao tiếp thông thạo (phần lớn làm hướng dẫn viên, lễ tân khách sạn và nhân viên thị trường), còn lại $85 \%$ chỉ đạt mức cơ sở. Trình độ ngoại ngữ yếu, kỹ năng nghiệp vụ còn thiếu đã hạn chế các đơn vị du lịch khai thác hết được nguồn lợi du lịch từ khách nước ngoài.

Chương trình đào tạo du lịch giữa các cơ sở rất khác nhau và nhìn chung quá thiên về trang bị kỹ năng mà không quan tâm đến trau dồi kiến thức nền, do đó chỉ tạo đội ngũ "thợ" chưa thể tạo ra những người quản lý giỏi, có cơ sở đào tạo tỷ lệ dạy thực hành rất thấp, dẫn đến kỹ năng nghề của sinh viên yếu. Trình độ sư phạm, chuyên môn của đội ngũ giảng viên du lịch cũng còn mỏng, chưa có trình độ chuyên sâu về du lịch. Nhiều giảng viên chuyển từ ngành khác sang giảng dạy cho nên thiếu sự hiểu biết sâu sắc và toàn diện về lý luận cũng như kinh nghiệm thực tế, lực lượng lãnh đạo, quản lý ở các cơ sở phần lớn còn yếu về năng lực chuyên môn, phương pháp quản lý. Cơ chế phối hợp giữa nhà trường và doanh nghiệp vẫn chưa rõ ràng, chưa có cơ chế, chính sách cụ thể, khả thi khuyến khích các doanh nghiệp thực sự quan tâm phối hợp với các cơ sở đào tạo trong đào tạo nhân lực du lịch. Bên cạnh đó, các cơ sở đào tạo cũng thiếu sự liên kết với nhau. Lao động ngành du lịch còn thiếu tính chuyên nghiệp và các kỹ năng mềm trong khi đặc trưng là ngành phục vụ và mang đến niềm vui, sự thư giãn cho con người, những yêu cầu, quy tắc về thái độ ứng xử, tính chuyên nghiệp trong phong cách làm việc, giữ gìn hình ảnh,... đang ngày càng được đề cao, trở thành những tiêu chí để đánh giá chất lượng nguồn nhân lực du lịch.

\subsection{Thụcc trạng khách du lịch quốc tế của Việt Nam hiện nay}

Theo số lượng thống kê của Tổng cục Du lịch Việt Nam, lượng du khách quốc tế đến Việt Nam năm 2018 lần đầu tiên đạt 15.497.791 lượt khách, tăng 19,9\% so với năm 2017 và gấp gần 
4 lần năm 2007, kể từ khi Việt Nam gia nhập WTO (2007) đến nay (hình 2). Lượng du khách đến Việt Nam ngày càng tăng và khách Việt nam đi du lịch trong nước và nước ngoài cũng tăng trưởng kỷ lục đạt gần 80 triệu lượt người, tổng thu từ khách du lịch 637.000 tỷ đồng; đóng góp trực tiếp của du lịch vào GDP khoảng 8,39\%. Tuy nhiên so với một số nước ASEAN, số lượng khách quốc tế đến nước ta còn thấp (Hình 3).

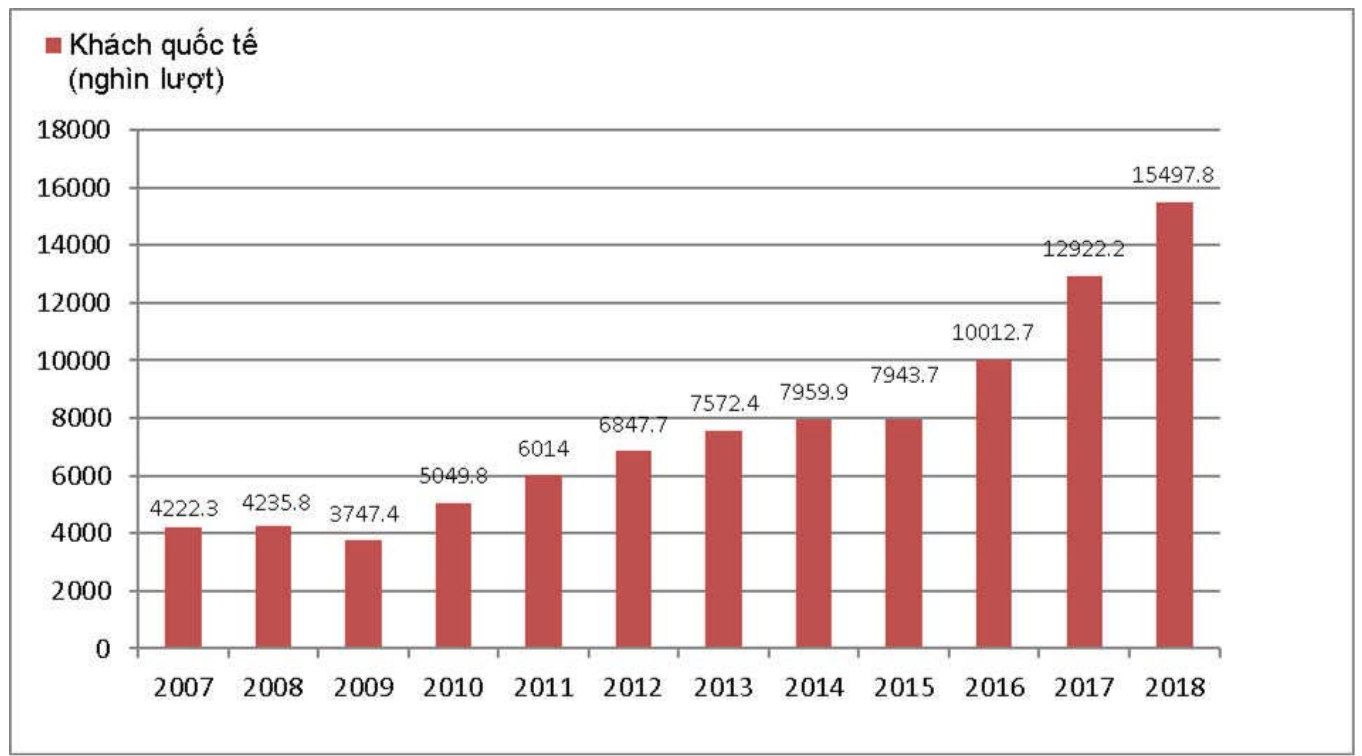

Hình 2. Lương khách quốc tế du lịch vào Việt Nam giai đoạn 2007- 2018 [11]

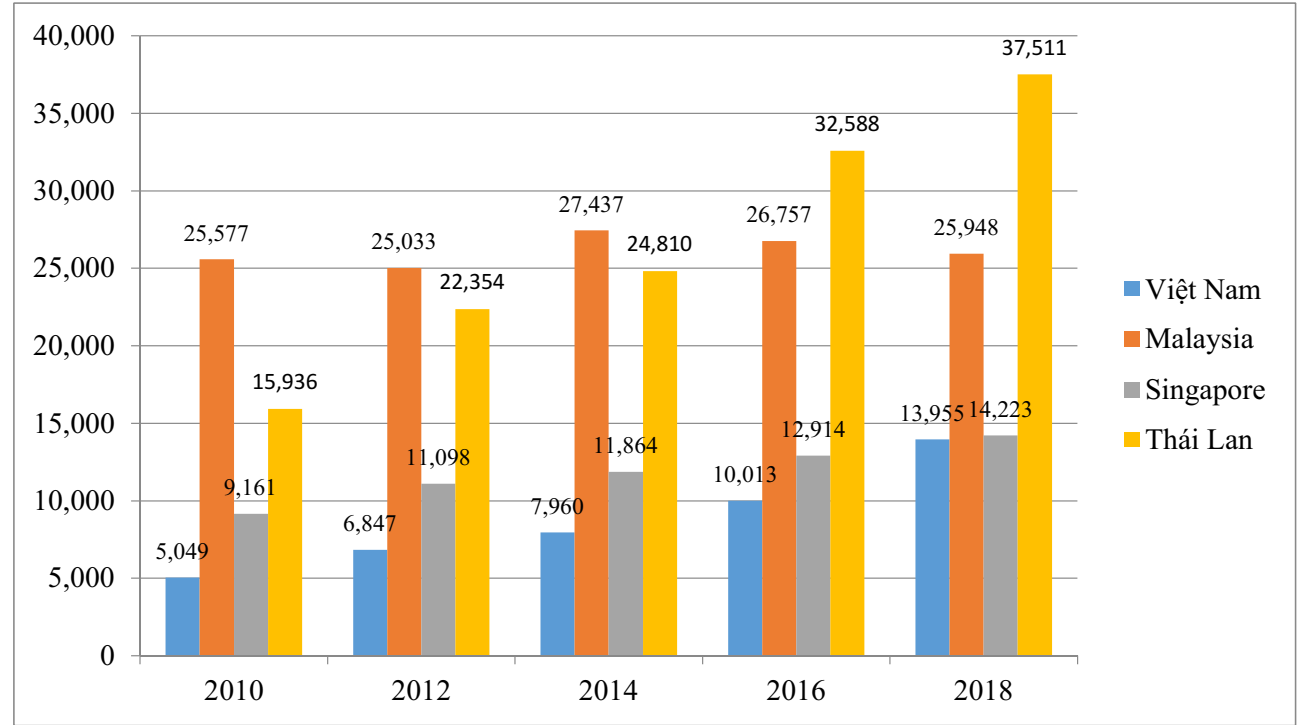

Hình 3. Khách quốc tế đến Việt Nam và một số nước ASEAN, 2010 - 2017 [11]

Hạ tầng du lịch và cơ sở vật chất kỹ thuật ngành $\mathrm{Du}$ lịch ngày càng phát triển. Loại hình sản phẩm, dịch vụ du lịch ngày càng phong phú và đa dạng. Chất lượng và tính chuyên nghiệp từng bước được nâng cao. Lực lượng doanh nghiệp du lịch lớn mạnh cả về số lượng và chất lượng, tạo được một số thương hiệu có uy tín ở trong nước và quốc tế.

\subsection{Nhũng vấn đề đặt ra đối với nguồn nhân} lục du lịch trong cách mạng công nghiệp 4.0

Trong cách mạng công nghiệp 4.0, ngành Du lịch được xem như có cơ hội lớn trong xu thế phát triển trí tuệ nhân tạo $(\mathrm{AI})$ và internet vạn vật (IoT), thực tế ảo, robot, điện toán đám mây, mạng xã hội, số hóa hay big data khi kết hợp sự phục vụ con người, để có thể đưa ra các nhận 
định, phân tích hiện trạng hoạt động của ngành; khai thác tối đa tiềm năng, tài nguyên du lịch; dự báo và hoạch định các chính sách, chiến lược phát triển du lịch cho phù hợp từng đối tượng và hoàn cảnh, tạo nên nhiều hiệu quả truyền thông và tiếp cận, đáp ứng nhu cầu đa dạng của từng cá nhân với sự sáng tạo và thông minh của công nghệ [5]. Cách mạng công nghiệp 4.0 chính thức diễn ra ở nước ta trong những năm gần đây, khái niệm “ Du lịch thông minh” ra đời, đây là ngành dịch vụ được phát triển trên nền tảng ứng dụng thành tựu khoa học và công nghệ hiện đại, đặc biệt là công nghệ thông tin truyền thông nhằm tạo ra những giá trị, lợi ích, dịch vụ tốt nhất, đáp ứng nhu cầu đa dạng của du khách, doanh nghiệp.

Đối với du khách, đầu tiên phải tìm địa chỉ, tìm trên mạng, tìm kiếm chỗ lưu trú, các phương tiện đi lại và giá cả hợp lý nhất, mua vé máy bay rồi các chỉ dẫn đường đi..., điều này đòi hỏi các doanh nghiệp du lịch cần phải sẵn sàng cho sự chuyển đổi mạnh mẽ sang công nghệ số hóa. Đồng thời cần trả lời các câu hỏi: Khi khách du lịch tới Việt Nam, hoặc khách Việt Nam đi du lịch tới các điểm đến mới, họ không biết sẽ phải đi đâu?, ở đâu? ăn gì? xem gì? mua gì?... Hiện nay, tất cả các thông tin đó được số hóa trên các ứng dụng có thể cài đặt lên điện thoại di động, dữ liệu số đã trở thành yếu tố quan trọng đối với doanh nghiệp du lịch, do vậy đội ngũ nhân sự của ngành du lịch Việt Nam cần phải nắm vững các kiến thức và kỹ năng liên quan đến ứng dụng Cách mạng công nghiệp 4.0 vào hoạt động du lịch.

Về phía các cơ sở đào tạo, đội ngũ giảng viên, phần lớn đều có trình độ, chuyên môn cao, dày dặn kinh nghiệm có khả năng truyền đạt tốt cho sinh viên nhiều kiến thức trên lớp học, tuy nhiên vẫn chưa thật sự khai thác tối đa và cập nhật lượng kiến thức mới, chưa tích cực trong việc ứng dụng các thiết bị công nghệ trong tìm kiếm thông tin, chưa đẩy mạnh hướng dẫn, đào tạo sinh viên nghiên cứu thực hành thông qua môi trường mạng, những kiến thức mang tính thực tế này sinh viên vẫn còn tiếp thu thông qua lý thuyết và sự truyền đạt từ phía giảng viên. Các khâu như đặt vé máy bay, vé xe, nhà hàng, khách sạn, món ăn....hầu như sinh viên thiếu thực hành nên sinh viên vẫn chưa thật sự nắm bắt rõ về quy trình thực tế cũng như những lưu ý cần thiết khi thực hiện những quy trình này. Vì thế, để đáp ứng nhu cầu hiện nay, các cơ sở đào tạo cần đẩy mạnh hướng dẫn, đào tạo sinh viên nghiên cứu thực hành thông qua môi trường mạng.

Với sự tiện dụng của mạng xã hội, hầu như giảng viên và sinh viên đều sử dụng nhưng việc vận dụng mạng xã hội vào trong học tập thì còn khá hạn chế. Vấn đề này một phần do điều kiện về phương tiện, công cụ hỗ trợ, hay chính sách của nhà trường vẫn chưa đáp ứng cho việc vận dụng mạng xã hội trong giảng dạy. Trên thực tế, Việt Nam ở vị trí thứ 17 trong bảng xếp hạng những quốc gia có mức độ phổ cập Internet hàng đầu thế giới và có hơn $53 \%$ dân số sử dụng Internet hàng ngày. Ngoài ra, có $90 \%$ khách du lịch nước ngoài đến Việt Nam tra cứu thông tin du lịch qua internet. Đây là yêu cầu để việc đào tạo trong các nhà trường cần thay đổi các phương pháp và phương tiện dạy học truyền thống và cũng là những lợi thế của doanh nghiệp phát triển một nền tảng du lịch thông minh nhờ ứng dụng những thành tựu của cuộc cách mạng công nghiệp 4.0.

Một số cơ sở đào tạo Du lịch vẫn còn hạn chế trong việc đưa tiếng Anh chuyên ngành vào chương trình giảng dạy du lịch, môi trường thực hành giao tiếp cho sinh viên vẫn chưa có trong khi sinh viên thì còn khá thụ động trong việc tạo cơ hội để cải thiện khả năng giao tiếp của bản thân. Nếu không giỏi ngoại ngữ, những nhân viên trong ngành du lịch cũng khó hoàn thành tốt nhiệm vụ và phát triển nghề nghiệp chuyên môn, không thể giúp khách du lịch hiểu tường tận về văn hóa Việt Nam và quảng bá hình ảnh đất nước ra bên ngoài, do vậy cần quan tâm đào tạo sinh viên du lịch khi tốt nghiệp ra trường với khả năng tiếng Anh tốt.

4.4 Nhũng giải pháp phát triển nguồn nhân lục du lịch trong xu thế hội nhập và cuộc cách mạng công nghiệp 4.0

Có cơ chế, chính sách ưu tiên đào tạo nhân lực du lịch: Thực hiện Nghị quyết số 08-NQ/TW 
ngày 16/01/2017 của Bộ Chính trị khoá XII về phát triển du lịch trở thành ngành kinh tế mũi nhọn [1]; Thông báo kết luận số 469/TB-VPCP ngày 06/10/2017 của Văn phòng Chính phủ về tình hình đào tạo nhân lực du lịch, trên cơ sở đó, Bộ Giáo dục và Đào tạo ban hành Công văn số 4929/BGDĐT-GDĐH ngày 20/10/2017 hướng dẫn cơ chế đặc thù đào tạo nhân lực ngành du lịch trình độ đại học giai đoạn 2017-2020 theo hướng đáp ứng tốt hơn yêu cầu của thị trường lao động và hội nhập quốc tế như: Khuyến khích thực hiện hình thức đào tạo văn bằng thứ hai ngành du lịch; khuyến khích các cơ sở đào tạo linh hoạt mở ngành đào tạo nhân lực du lịch theo nhu cầu của thị trường lao động và hội nhập quốc tế; các cơ sở đào tạo chủ động liên kết đào tạo với doanh nghiệp được tự chủ xác định chỉ tiêu tuyển sinh theo hướng, mở rộng quy mô đối với các ngành đào tạo về du lịch; phân tích mức độ đáp ứng yêu cầu công việc của sinh viên tốt nghiệp nhóm ngành du lịch, các cơ sở đào tạo xác định chỉ tiêu tuyển sinh, điều chỉnh chương trình đào tạo phù hợp với thị trường lao động ngành du lịch...

Thay đổi toàn diện mục tiêu đào tạo tại các cơ sở đào tạo, tiêu chuẩn hóa nhân lực du lịch theo chuẩn khu vực và quốc tế: Sử dụng đội ngũ giảng viên có đủ trình độ chuyên môn nghiệp vụ nghề nghiệp, tay nghề cao để giảng dạy lý thuyết và hướng dẫn thực hành nâng cao tay nghề cho người học. Xây dựng hoàn thiện và ban hành thực hiện chương trình đào tạo chuẩn theo hướng ứng dụng nghề nghiệp, có cập nhật bổ sung khi tiếp cận các chương trình tiên tiến và sự góp ý của các cơ sở sử dụng lao động. Nhanh chóng áp dụng các chương trình đào tạo chuẩn khu vực và thế giới, đào tạo theo hướng mở, để khai thác tiềm lực từ các doanh nghiệp kinh doanh du lịch.

Nhằm nâng cao chất lượng dịch vụ du lịch tại Việt Nam cũng như hiệu quả đào tạo nghề du lịch, chương trình Phát triển Năng lực Du lịch có trách nhiệm với Môi trường và Xã hội, do Liên minh châu Âu tài trợ (Dự án EU) đã sửa đổi bộ Tiêu chuẩn Kỹ năng nghề Du lịch Việt Nam (VTOS) [4], người lao động, người sử dụng lao động, giáo viên và học sinh các trường du lịch tiếp cận, áp dụng và thực hiện theo tiêu chuẩn VTOS nhằm nâng cao chất lượng dịch vụ du lịch cũng như hiệu quả đào tạo nghề du lịch một cách thống nhất. Các cơ sở đào tạo và dạy nghề rà soát chương trình đào tạo và văn bằng để đảm bảo rằng chúng phù hợp với chương trình $\mathrm{du}$ lịch chung ASEAN, đáp ứng các yêu cầu của ASEAN về thừa nhận văn bằng du lịch lẫn nhau...

Thực hiện hiệu quả mối quan hệ hợp tác giữa nhà trường với các doanh nghiệp

Các cơ sở đào tạo cần chủ động trao đổi, tìm kiếm những lợi thế kết nối hợp tác chặt chẽ với các doanh nghiệp, đặc biệt là doanh nghiệp du lịch để dự báo nhu cầu lao động, xây dựng chuẩn đầu ra và đào tạo sinh viên có kỹ năng đáp ứng yêu cầu ngành nghề. Các doanh nghiệp vừa có vai trò hỗ trợ các hoạt động đào tạo về nghiệp vụ, vừa là nơi sử dụng lao động của các cơ sở đào tạo cả trước mắt và lâu dài; là nơi thực hành, thực tập của cơ sở đào tạo; sử dụng cơ sở vật chất, trang thiết bị, phần mềm... của doanh nghiệp để đào tạo thực hành (thời gian đào tạo tại các doanh nghiệp ít nhất bằng tổng thời gian thực hành, thực tập của chương trình đào tạo và không ít hơn $50 \%$ tổng thời gian thực hiện chương trình đào tạo, doanh nghiệp cử chuyên gia tham gia giảng dạy, hướng dẫn thực hành, thực tập, đánh giá kết quả học tập của sinh viên...) trên cơ sở đó đào tạo được nguồn nhân lực du lịch đáp ứng theo nhu cầu của khách du lịch theo chuẩn mực khu vực và quốc tế.

Phát triển nguồn nhân lực du lịch với khả năng sử dụng và ứng dụng khoa học công nghệ, phát triển du lịch thông minh

Phát triển khoa học và công nghệ phải thực sự trở thành động lực phát triển của ngành $\mathrm{Du}$ lịch, gắn liền với nhiệm vụ quản lý nhà nước và hoạt động khai thác, kinh doanh du lịch, đổi mới cơ chế, tăng cường tiềm lực; gắn nghiên cứu với ứng dụng, góp phần thực hiện các chiến lược và chính sách; giải quyết các vấn đề thực tiễn đặt ra, thúc đẩy phát triển du lịch. Khuyến khích và tạo điều kiện thuận lợi cho sáng tạo, sáng chế, phát minh khoa học và công nghệ gắn với nghiên cứu và đào tạo. Thúc đẩy tạo lợi ích về kinh tế từ 


\section{BÀI BÁO KHOA HỌC}

kết quả nghiên cứu ứng dụng đi đôi với tăng cường quản lý và kinh doanh du lịch. Tăng cường hội nhập, hợp tác quốc tế, đẩy mạnh thu hút các nguồn lực trong và ngoài nước ứng dụng khoa học và công nghệ trong cơ cấu lại ngành du lịch.

\section{Kết luận}

Trong xu thế hội nhập và phát triển như vũ bão của cuộc cách mạng công nghiệp 4.0, nhu cầu đào tạo và sử dụng nguồn nhân lực du lịch chất lượng cao có ý nghĩa quyết định để đưa du lịch trở thành ngành kinh tế mũi nhọn và hội nhập với quốc tế. Thời gian qua, việc đào tạo nguồn nhân lực du lịch ở nước ta đạt được những thành tựu quan trọng, đã xây dựng được hệ thống đào tạo nguồn nhân lực từ sơ cấp đến đại học, sau đại học. Đội ngũ nguồn nhân lực được đào tạo đã góp phần quan trọng đưa ngành Du lịch Việt Nam phát triển mạnh trong những năm qua, đóng góp vào phát triển kinh tế - xã hội, đem hình ảnh của Việt Nam ra bạn bè quốc tế. Tuy nhiên, so với yêu cầu ngày càng cao của thực tiễn, hình thành nhiều lĩnh vực du lịch mới thì nguồn nhân lực du lịch Việt Nam còn bộc lộ những hạn chế. Những giải pháp quan trọng cần thực hiện để nâng cao chất lượng nguồn nhân lực du lịch như: có cơ chế, chính sách ưu tiên đào tạo nhân lực du lịch; thay đổi mục tiêu đào tạo, xây dựng đội ngũ giảng viên vững vàng về chuyên môn nghiệp vụ, đáp ứng yêu cầu hội nhập, đổi mới nội dung chương đào tạo theo hướng chuẩn hóa, hiện đại hóa, tiếp cận dần yêu cầu năng lực làm việc trong các lĩnh vực của ngành, trình độ tiên tiến của khu vực và thế giới; đẩy mạnh hoạt động liên kết đào tạo giữa các cơ sở đào tạo với doanh nghiệp, hướng tới đạt chuẩn quốc tế về chất lượng đào tạo; tăng cường cơ sở vật chất, nhất là công nghệ thông tin phục vụ việc nghiên cứu, giảng dạy, học tập là yếu tố rất quan trọng trong thời kỳ công nghiệp 4.0 để nâng cao chất lượng đào tạo nguồn nhân lực du lịch trong bối cảnh hội nhập.

\section{Tài liệu tham khảo}

1. Ban chấp hành Trung ương Đảng (2017), Nghị quyết số 08-QĐ/TW của Bộ Chính tị về phát triển du lịch trở thành ngành kinh tế mũi nhọn.

2. Bộ Văn hóa, Thể thao và Du lịch (2016), Đề án tăng cuờng đào tạo theo nhu cầu xã hội lĩnh vực du lịch đến năm 2025, tầm nhì đến 2030.

3. Phạm Xuân Hậu (2019), Phát triển nguồn nhân lực du lịch chất lương cao ở Việt Nam trong bối cảnh hội nhập- sụ̣ lựa chọn nhũng giải pháp phù hợp" ISBN- 978-604-73-7107-5, NXB ĐHQG Thành Phố Hồ Chí Minh.

4. Hệ thống tiêu chuẩn VTOS (2013), Chương trình Phát triển năng lực Du lịch có trách nhiệm với môi truờng và xã hội (Dự án EU), Tổng cục Du lịch.

5. Klaus Schwab (2018), Cách mạng Công nghiệp lần thứ tur, Nxb. Chính trị quốc gia Sự thật.

6. Phạm Trung Lương (2016), Đào tạo phát triển nguồn nhân lực du lịch trong bối cảnh hội nhập. Kỷ yếu Hội thảo Brexit và cộng đồng kinh tế ASEAN dưới góc nhìn hội nhập. Trường Đại học Văn Hiến.

7. Nguyễn Minh Tuệ, Vũ Đình Hòa (2017), Địa lý du lịch cơ sở lý luận và thực tiễn phát triển ở Việt Nam. NXB Giáo dục.

8. Thủ tướng Chính phủ (2011), Quy hoạch tổng thể phát triển du lịch Việt Nam đến năm 2020, tầm nhìn đến năm 2030.

9. Lê Sĩ Trí (2018), Quảng bá du lịch trong thời kỳ CMCN 4.0, nhũng vấn đề đặt ra và kiến nghị. Kỉ yếu Hội thảo "Phát triển du lịch trong cách mạng công nghiệp 4.0" ISBN- 978-604-73-5980-6, NXB ĐHQG Thành Phố Hồ Chí Minh.

10. Lê Anh Tuấn (2019), Chủ trưong, chính sách của Đảng và Nhà nước về phát triển nguồn nhân lục du lịch. ” ISBN- 978-604-73-7107-5. NXB ĐHQG Thành Phố Hồ Chí Minh.

11. Viện Nghiên cứu Phát triển Du lịch (2018), Báo cáo phục vu Chiến lược tổng thể phát triển khu vục dịch vu Việt Nam giai đoạn 2021 - 2030, tầm nhìn đến năm 2050. 


\title{
TRAINING HIGH-QUALITY HUMAN RESOURCES IN TOURISM IN THE TREND OF INTEGRATION AND THE INDUSTRIAL REVOLUTION 4.0
}

\author{
Le Thi Le ${ }^{1}$
}

${ }^{1}$ Thanh Hoa University of Culture, Sports and Tourism

\begin{abstract}
In the trend of international integration and the impact of the Industrial Revolution 4.0, high-quality human resources in tourism plays a decisive role in tourism development and significantly contribute to the implementation of national renewal. The article analyzes the current situation of training tourism human resources in Vietnam, its achievements and limitations, and studies the impact of the Industrial Revolution 4.0 which sets the requirements and opportunities for the training of high-quality human resources in tourism. Accordingly, a number of solutions are proposed to create a breakthrough in the training of high-quality human resources in tourism in the integration era, and to render the tourism industry to a key economic sector.
\end{abstract}

Keywords: Human resources, tourism, human resource training, integrated tourism, Industry 4.0. 